
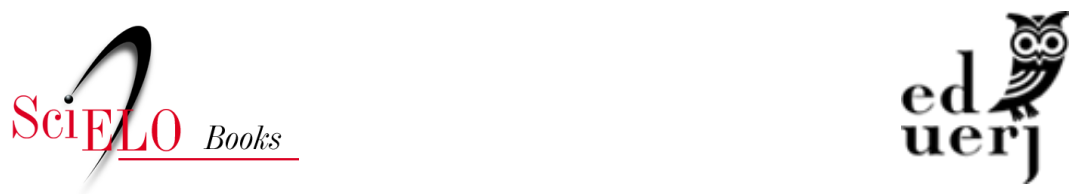

\title{
Uma panela com várias colheres: a experiência do CRO
}

\author{
Phillipe Augusto Ferreira Rodrigues \\ Luciana da Silva Rodriguez \\ Caroline Niquini de Assis \\ Raquel de Lima Soeiro \\ Jorginete de Jesus Damião \\ Juliana Pereira Casemiro
}

\section{SciELO Books / SciELO Livros / SciELO Libros}

RODRIGUES, P. A. F., RODRIGUEZ, L. S., ASSIS, C. N., SOEIRO, R. L., DAMIÃO, J. J., and CASEMIRO, J. P. Uma panela com várias colheres: a experiência do CRO. In: Sistematização de experiências de trabalho com grupos nos Centros de Referência em Obesidade/RJ [online]. Rio de Janeiro: EDUERJ, 2020, pp. 19-24. ISBN: 978-65-87949-15-4. https://doi.org/10.7476/9786587949154.0004.

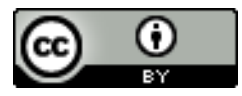

All the contents of this work, except where otherwise noted, is licensed under a Creative Commons Attribution 4.0 International license.

Todo o conteúdo deste trabalho, exceto quando houver ressalva, é publicado sob a licença Creative Commons Atribição 4.0.

Todo el contenido de esta obra, excepto donde se indique lo contrario, está bajo licencia de la licencia Creative Commons Reconocimento 4.0. 


\section{Uma panela com várias colheres: a experiência do CRO}

Os Centros de Referência em Obesidade foram oficialmente instituídos em 15 de julho de 2011, por meio de uma publicação no Diário Oficial do Município do Rio de Janeiro. O primeiro deles foi inaugurado no bairro de Acari, composto por uma equipe multiprofissional responsável pela cobertura de $100 \%$ da populaçáo adstrita ao território.

Inicialmente, esse serviço foi intitulado Centro de Referência do Obeso e sua criação ocorreu de forma verticalizada. Nesse primeiro momento, tanto a nomeaçáo do espaço quanto a perspectiva de como se daria a estruturaçáo do serviço eram incipientes. A organização da RAS para o cuidado da obesidade era uma questão emergente, não existindo as atuais portarias e proposta de linhas de cuidado direcionada ao cuidado desse público, como pode ser visto na figura a seguir: 
Figura 1 - Linha do tempo das políticas públicas nacionais ao longo da existência do CRO

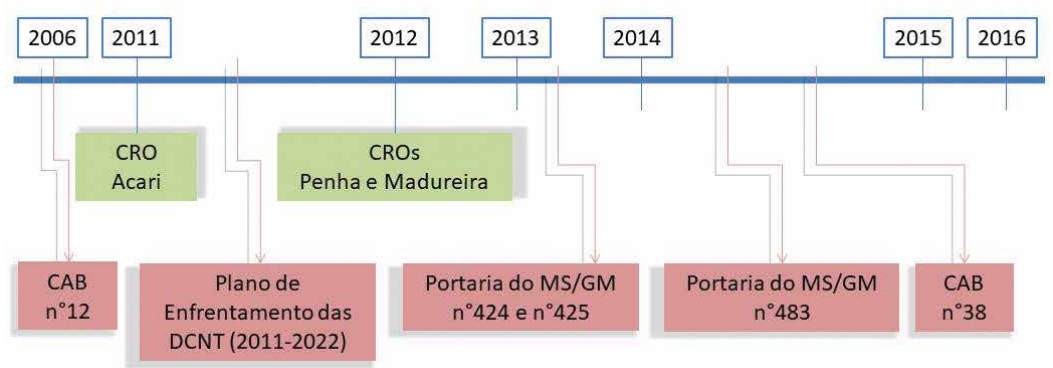

Fonte: autoria própria.

Essa linha do tempo localiza o momento no qual os CROs se inserem e como eles se relacionam no contexto de movimentaçáo das políticas públicas nacionais voltadas para o enfrentamento da obesidade.

Nota-se que, no momento da constituição da primeira unidade, existia apenas o CAB n. ${ }^{\circ} 12$ (BRASIL, 2006). Ele era o único documento norteador para o manejo clínico, atividades educativas, estratégias e açóes voltadas para esse público. Pode-se dizer que atravessava na equipe certo sentimento de desamparo, visto que a maior parte das experiências encontradas na literatura era segmentada ou relacionada à abordagem cirúrgica da obesidade. A proposta de construção de uma abordagem clínica-ambulatorial interdisciplinar era uma inovaçáo e, por isso, coexistia com o sentimento de solidáo e desamparo um mundo de possibilidades a ser experimentado. Muito do aprendizado e experiências construídos no CRO foi baseado em tentativas e erros, até encontrar caminhos mais acertados. O denominador comum nas apostas feitas era o de abordar os usuários do serviço como sujeitos de sua própria vida, com desejos, limites e principalmente potencialidades. Essa premissa permitiu que as abordagens dos profissionais se orientassem pela melhoria da qualidade de vida e desenvolvimento de autonomia dos usuários. 
Nesse processo de organização, estruturação e implantação do serviço, o CRO contou com o apoio do Instituto de Nutrição Annes Dias (INAD) como referência técnica para os profissionais. Uma das primeiras mudanças propostas ao longo do processo de consolidação do serviço foi sua nomenclatura. O nome "Centro de Referência do Obeso" causava grande incômodo, pois reduzia o sujeito obeso à sua doença. Isso levou a que se optasse, posteriormente, pela sua troca, passando a ser chamado de "Centro de Referência em Obesidade". Ainda que abarcasse essa condição patológica, passou a ser orientada pela questão ética da complexidade.

No ano seguinte, houve a expansão desses serviços com a inauguração das unidades nos bairros Penha e Madureira, o que levou a uma redefiniçáo da cobertura dessas unidades no município do Rio de Janeiro. O novo desafio era o de manter um serviço de qualidade, acessível para a maior parte da população, considerando a carga horária de 20 horas semanais dos profissionais que se distribuem entre o desenvolvimento de atividades de gestão, planejamento e assistência.

Todos os CROs foram alocados no interior de Clínicas da Família (CF) com a intenção de estar mais próximo das ações de saúde realizadas no território de atuação das equipes da Estratégia de Saúde da Família. Esse posicionamento estratégico dos CROs facilitaria a longitudinalidade do cuidado, de forma que o usuário pudesse transitar mais facilmente pela rede de serviços disponíveis, além de promover uma maior integraçáo assistencial por todo o contínuo de atençáo e ajudar no desenvolvimento e capacitaçáo de recursos humanos nessa área.

No entanto, no ano de 2016, as unidades Acari e Madureira foram ambas deslocadas e tiveram suas atividades concentradas no Hospital Municipal Ronaldo Gazolla, no bairro de Acari. Ainda que oficialmente vinculado à Clínica da Família Marcos Valadáo, as equipes utilizam um espaço cedido pelo hospital, localizado no mesmo terreno da CF. 
Destaca-se que a proposta de atuação interdisciplinar propicia um olhar ampliado sobre o usuário que qualifica o projeto terapêutico singular (PTS), principalmente pelo fato de ele participar das decisóes sobre seu próprio tratamento, considerando-o ativo nesse processo e valorizando todos os espaços de diálogo possíveis.

Definiu-se, como pontos de corte para a admissão no serviço, sujeitos obesos que apresentassem Índice de Massa Corporal (IMC) superior a $40 \mathrm{~kg} / \mathrm{m}^{2}$, associado ao diagnóstico de diabetes, ou IMC superior a $50 \mathrm{~kg} / \mathrm{m}^{2}$, independentemente de comorbidades associadas. Esses critérios tinham por objetivo oferecer assistência a um segmento mais grave da obesidade que encontrava entraves no acesso a serviços de saúde. Isso pode ser notado quando unidades básicas de saúde não apresentam, em geral, nem mobiliário, nem instrumentos adequados para o atendimento desses usuários. As próprias balanças suportam, em geral, até $150 \mathrm{~kg}$, os aparelhos de aferição da pressão arterial não alcançam a circunferência do braço e, ainda, há ausência de cadeiras ou macas que suportem o peso desses usuários, de modo que a realização de alguns exames fica prejudicada.

Uma vez que o perfil populacional se alterou ao longo dos anos, a rede de serviços deveria estar preparada para acolher essa demanda. Porém, não é o que acontece. Falta mobiliário básico que sustente o excesso de peso apresentado por boa parte desse segmento da obesidade, e o mesmo acontece com vagas para internação e exames mais complexos.

A ideia, portanto, era a de priorizar o atendimento àqueles que teriam maiores dificuldades de acessar esses dispositivos, visto que outros segmentos da obesidade poderiam ser acompanhados na ESF ou em ambulatórios outros.

Atualmente, o fluxo de entrada e acompanhamento dos usuários está representado na figura 2. A porta de entrada do serviço é o "Grupo de Acolhimento". Nesse primeiro momento, é observado se os usuários encaminhados atendem aos critérios de inclusão, e 
são esclarecidos os objetivos, funcionamento e as principais dúvidas sobre o serviço e o acompanhamento clínico. Os usuários inseridos no programa participam de encontros no chamado "Grupo de Conhecimento em Saúde”, cujo objetivo é orientar sobre a obesidade e as principais comorbidades, tratamentos medicamentosos e a importância de mudança de estilo de vida. Todos passam por avaliação com todos os profissionais e, em paralelo às consultas individuais, os usuários participam dos grupos multiprofissionais e oficinas, como o "Grupo Saúde em Foco", que aborda questóes gerais sobre saúde, "Grupo Corpo em Movimento", voltado para atividade física, "Grupo Terapêutico", coordenado pelo psicólogo, e as "Oficinas Culinárias".

Figura 2 - Fluxo de entrada e acompanhamento dos usuários no CRO
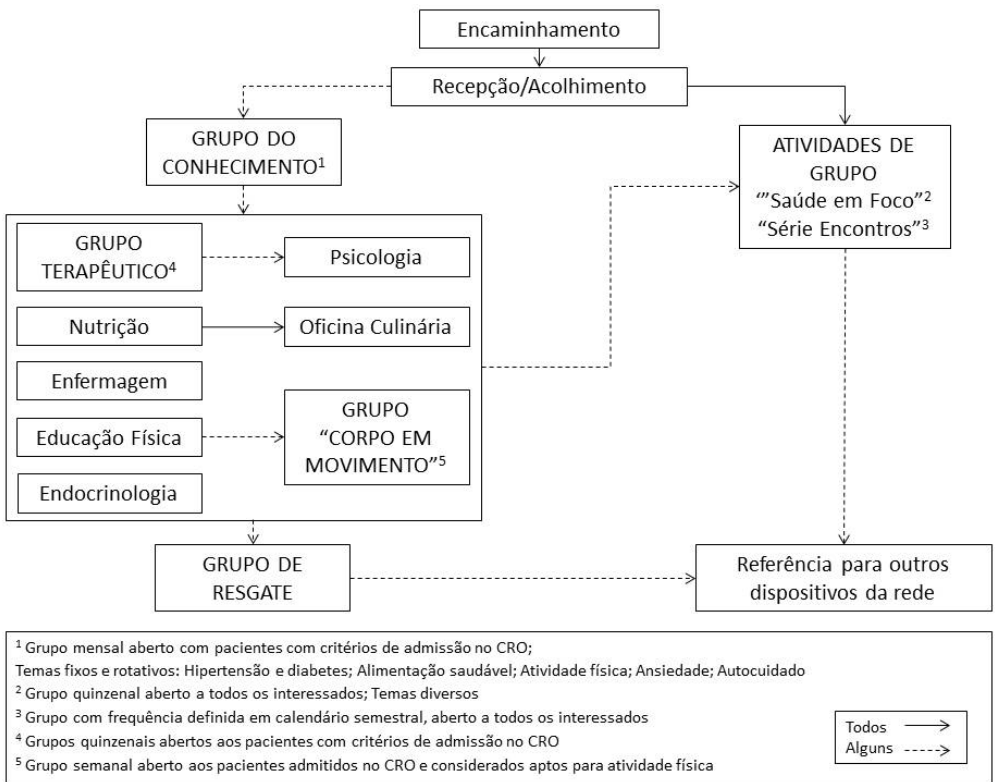

Fonte: Protocolo do CRO. 
As atividades em grupo são uma das estratégias para o cuidado adotadas no CRO, consideradas de grande importância, visto sua potência em promover troca de vivências, dificuldades enfrentadas, experiências adquiridas e construçấo de estratégias que diminuam seu isolamento social.

Cabe ainda ressaltar que, para além das demandas supracitadas, os CROs estão disponíveis para discussão de casos e matriciamento de equipes da ESF, entre outras atividades. Anualmente, o serviço organiza Seminário de Enfrentamento da Obesidade, voltado para os profissionais da rede. Já foram desenvolvidas, até o presente momento, três ediçóes com o intuito de compartilhar experiências do manejo clínico da obesidade e vivências de atividade em grupo na rede de serviços. 